\title{
Participação, Controle Social e Exercício da Cidadania: a (des)informação como obstáculo à atuação dos conselheiros de saúde*
}

I 'Rosângela Minardi Mitre Cotta, '2Mariana de Melo Cazal, 3Jôsi Fernandes de Castro Rodrigues I

R esumo: Para fortalecer o exercício do controle social na política de saúde, é necessário o efetivo conhecimento do SU S; da legislação; da realidade epidemiológica, assistencial, financeira, política, etc. N este sentido, o presente estudo objetivou dimensionar o nível de informação e conhecimento dos Conselheiros M unicipais de Saúde de Viçosa - M G, em relação a suas atribuições e funções. O s elementos de análise do estudo foram: entrevistas semiestruturadas, no período de abril a julho de 2006, e a observação direta das reuniões. D o total de 44 conselheiros, 34 (77,3\%) foram entrevistados; destes, 17 (50\%) são representantes dos usuários, oito $(23,5 \%)$ são representantes do G overno M unicipal, sete $(20,6 \%)$ são representantes dos prestadores de serviço e dois (5,9\%) são representantes dos profissionais de saúde. 0 bserva-se que 41,2\% de conselheiros desconhecem o Regimento Interno, o que poderia estar dificultando o exercício de suas competências. O Plano M unicipal de Saúde não é utilizado como um instrumento de consulta para avaliação das ações e serviços de saúde pelos conselheiros, pois a maioria $(73,5 \%)$ afirma não o ter lido. A possibilidade de os conselheiros contribuírem para fiscalizar as execuções financeiras e orçamentárias do Fundo de Saúde M unicipal se torna restrita, pois $67,6 \%$ dos entrevistados não sabem analisar o Relatório de G estão; 79,4\% dos consel heiros nunca receberam capacitação e 85\% relataram sentir necessidade de ser capacitados para atuar no consel ho. A participação e o controle social conferem transparência ao bem público e, partindo do pressuposto que só se pode controlar aquilo que se conhece, justifica-se a necessidade contínua de cursos de capacitação para os conselheiros.

\author{
${ }^{1}$ Doutora em Saúde Pública \\ pela Universidad de Valencia, \\ Espanha; professora adjunta de \\ Política de Saúde, \\ Departamento de Nutrição e \\ Saúde - Universidade Federal \\ de Viçosa (UFV), Viçosa, MG. \\ Endereço eletrônico: \\ rmmitre@ufv.br \\ 2 Graduanda em Nutrição/ \\ Bolsista de Iniciação Científica \\ - FAPEMIG - Universidade \\ Federal de Viçosa, \\ Departamento de Nutrição e \\ Saúde (UFV), Viçosa, MG. \\ ${ }^{3}$ Graduanda em Nutrição - \\ Universidade Federal de \\ Viçosa, Departamento de \\ Nutrição e Saúde (UFV), Viçosa, \\ MG.
}

Recebido em: 16/07/2008 Aprovado em: 11/04/2009. 


\section{Introdução}

D entre as inovações da reforma sanitária brasileira (RSB), destaca-se a ousada proposta de controle social. Durante o período ditatorial, o controle social significava o controle exclusivo do Estado sobre a sociedade, cerceando qualquer expressão popular, passando, a partir do processo de RSB, a significar o controle da sociedade sobre a ação do Estado (COT TA et al., 1998; 2006). Essa proposta se concretizou no Brasil principal mente com a institucionalização dos mecanismos de participação social - as Conferências e os Conselhos de Saúde - nas leis orgânicas da saúde (Leis no 8.080/90 e 8.142/90), como instâncias colegiadas de caráter permanente e deliberativo. D estarte, o controle social passa a ser considerado uma conquista, sendo a principal estratégia de garantia da descentralização e municipalização da saúde (CORREIA, 2005; WEN DH AU SEN ; CAPO NI, 2002; COTTA et al., 2006).

Segundo C unha (2003), o controle social conquistado pela sociedade civil deve ser entendido como instrumento e expressão da democracia. Busca-se, portanto, com a democratização, eliminar as formas tradicionais e autoritárias de gestão das políticas sociais, bem como a adoção de práticas que favoreçam a maior transparência das informações e da partici pação da sociedade no processo decisório (SILVA et al., 2007).

$M$ ais ainda, esta participação da sociedade deve transcender a extensão executiva e burocrática, passando a ser pensada como um processo contínuo de democratização, o que implica o estabelecimento de uma nova sociabilidade política e um novo espaço de cidadania, onde o sujeito-cidadão deve ser o centro do processo de aval iação das ações nos serviços de saúde (ASSI S; VILLA, 2003; COTTA et al., 2006). D e acordo com C hauí (1993), a cidadania ativa é aquela que institui o cidadão essencialmente como criador de direitos para abrir novos espaços de participação política.

O controle social passa a ser a pedra de toque do Sistema Ú nico de Saúde (SU S), resgatando os princípios constitucionais de universalidade, integralidade e equidade, viabilizando a qualidade dos serviços com a possibilidade concreta de inclusão dos usuários na pauta de decisões. Vale ressaltar, portanto, a visível necessidade de controle dos recursos públicos numa conjuntura globalizadora de diminuição de gastos sociais e en xugamento do Estado, associada à presença de situações que retratam o uso clientelístico dos recursos pelos governos locais, 
além da apropriação indevida dos recursos públicos por parte de organizações privadas (COTTA et al., 1998; 2006).

Esse contexto do controle social, concebido como a participação direta da sociedade civil sobre os processos de gestão dos recursos públicos, reflete a apropriação, pela sociedadeorganizada, dos meios einstrumentos de planejamento, fiscalização e análise das ações eserviços de saúde. Sua visibilidade está condicionada à existência de uma democracia participativa eà institucionalização dos canais de participação em consel hos setoriais (CO RREIA, 2005; GERSCH M AN , 2004). Sob esseaspecto, a efetivação do controlesocial na organização do SU Sérepresentada pelos Conselhos e Conferências de Saúde. Essas instâncias protagonizam a participação da sociedade na gestão do sistema earticulam atores sociais portadores de interesses diferentes e olhares distintos sobre a realidade, nem sempre convergentes, onde as disputas de poder estão presentes, embora os processos de discussão busquem o consenso em defesa dos princípios e diretrizes de um sistema público resolutivo e equânime (ASSIS; VILLA, 2003).

A aquisição desses espaços de participação foi primordial na organização de uma institucionalidade democrática, por meio da qual o direito à saúdenão poderia concretizar-se em direito à cidadania. D este modo, a saúde é reafirmada numa definição ampla e o direito a saúde é ressaltado como conquista social, que, para pleno exercício necessita garantir a participação da população na organização, gestão e controle das ações e serviços de saúde (GUIZARDI et al., 2004). Além disso, atualmente, as tentativas de criação dos Conselhos M unicipais constituem um bom ponto de partida para se avançar na via de renovação da luta democrática (M ARTIN S, 2008). Assim, na perspectiva de fortalecer o exercício do controle social na política de saúde, faz-se necessário, por parte dos sujeitos políticos envolvidos no processo, conhecer efetivamente o SUS, a legislação, a realidade epidemiológica, assistencial, financeira, política, etc., visando ao acompanhamento e avaliação do sistema de informações em saúde nos níveis municipal, estadual e federal (COTTA et al., 1998; SILVA et al., 2007).

$\mathrm{N}$ esse sentido, o presente estudo tem por objetivo dimensionar o nível de informação econhecimento dosC onselheirosM unicipais deSaúdedeViçosa(M G ), em relação a suas atribuições e funções, visando a definir estratégias a serem trabal hadas em programas e cursos de capacitação e educação continuada. 


\section{M etodologia}

0 estudo foi realizado na cidade de Viçosa, situada na região da Zona da M ata mineira, entre as Serras da M antiqueira, do C aparaó e da Piedade, distando 225 $\mathrm{K} \mathrm{m}$ de Belo H orizonte. A população residenteéde 64.910 habitantes, sendo que, destes, 59.896 (92,27\%) moram na zona urbana e 5.014 (7,73\%) na zona rural, segundo o último censo demográfico realizado pelo Instituto Brasileiro de $G$ eografia e Estatística (IBGE, 2000). Possui uma área territorial de $300,2 \mathrm{~km}^{2}$, densidade demográfica de $216,2 \mathrm{hab} / \mathrm{km}^{2}$ e uma altitude de $648 \mathrm{~m}$. 0 Índice de D esenvolvimento $H$ umano $M$ unicipal (ID H ) é 0,8 , sendo a renda per capita média de 329,70 (PNUD/IPEA/FJP, 2000).

Trata-se de um estudo cujos elementos de análise foram: entrevistas semiestruturadas, realizadas por um único entrevistador devidamente treinado, durante o período de abril a julho de 2006 e observação direta, não participante, das reuniões do C onselho M unicipal deSaúde(CM S). As entrevistas foram gravadas depois da autorização dos entrevistados, sendo posteriormente transcritas.

0 questionário elaborado pela equipe de pesquisadores e aplicado aos conselheiros abrange as seguintes dimensões: dados pessoais, conhecimento a respeito do papel do conselheiro e do CMS, nível de conhecimento sobre os documentos importantes para o exercício da função de conselheiros (R egimento Interno, Plano M unicipal deSaúdee Relatório de G estão) produzidos pelaSecretaria M unicipal de Saúde (SM S), conhecimento sobre as fontes de financiamento do SU S para o município e questões relacionadas à capacitação dos conselheiros de saúde para o exercício das atividades no CM S. D o total de 44 conselheiros (22 titulares e 22 suplentes), participaram da pesquisa 34 (77,27\%). D entre os dez $(22,73 \%)$ restantes, dois $(4,56 \%)$ não aceitaram participar, três $(6,83 \%)$ tinham os cargos vagos e cinco $(11,4 \%)$ não foram encontrados.

A confidencialidade dos dados foi assegurada. O ComitêdeÉtica em Pesquisa em Seres H umanos da Universidade Federal de Viçosa aprovou a pesquisa e os participantes do estudo assinaram um Termo deC onsentimento Livree Esclarecido.

A entrada de dados foi feita por meio do programa Excel (M icrosoft Corp., EU A) e os dados posteriormentetransportados para o SPSS versão 11.5 (SPSS I nc, Chicago, EU A), para realização da descrição e análise estatística. Foi elaborada a tabulação com frequências simples. 


\section{Resultados}

D o total deconsel heiros entrevistados, 17 (50\%) são representantes dosusuários, oito $(23,5 \%)$ do Governo M unicipal, sete $(20,6 \%)$ dos prestadores de serviço e dois $(5,9 \%)$ dos profissionais de saúde. A média de idade dos conselheiros foi 46,82 anos, variando entre 22 a 69 anos. A renda familiar (RF) mediana foi 5,85 salários mínimos (SM ), variando de 1 a $40 \mathrm{SM}^{1}$, sendo que $64,7 \%$ dos entrevistados apresentaram RF acima de quatro salários mínimos. Q uanto à escolaridade, a maioria $(67,6 \%)$ tinha ensino superior, $20,6 \%$ informaram ter ensino médio completo, $2,9 \%$ ensino fundamental completo e $8,8 \%$ tinham ensino fundamental incompleto.

No que se refere ao tempo de atuação no CM S, a mediana foi 18 meses, variando de dois a 192 meses, sendo que $82,35 \%$ dos consel heiros são membros do CM S a mais de 1 ano.

Conforme está demonstrado na tabela 1 , quanto à forma deingresso no CM S, destaca-se que 38,2 \% foram eleitos por seus pares e 32,4\% foram indicados pela diretoria da instituição. $M$ ais especificamente, no que se refere aos representantes dos usuários, 52,9\% foram eleitos entre seus pares e 29,4\% foram indicados, enquanto que $37,5 \%$ dos representantes do governo municipal foram indicados pelo prefeito. Ressalta-se, ainda, que $64,7 \%$ dos conselheiros da gestão atual já foram membros do CM S de V içosa em outra gestão.

\section{Tabela 1. Forma de ingresso dos conselheiros, por categoria, Conselho M unicipal de Saúde, Viçosa-M G (2006)}

\begin{tabular}{|c|c|c|c|c|c|c|c|c|}
\hline \multicolumn{9}{|c|}{ Categoria que representa no $\mathrm{CMS}$} \\
\hline & \multicolumn{2}{|c|}{ Usuários } & \multicolumn{2}{|c|}{$\begin{array}{c}\text { Governo } \\
\text { Municipal }\end{array}$} & \multicolumn{2}{|c|}{$\begin{array}{c}\text { Prestadores de } \\
\text { serviço }\end{array}$} & \multicolumn{2}{|c|}{$\begin{array}{c}\text { Profissionais de } \\
\text { saúde }\end{array}$} \\
\hline & $n$ & $\%$ & $n$ & $\%$ & $n$ & $\%$ & $n$ & $\%$ \\
\hline Indicado pela SMS & 1 & 5,9 & & & & & & \\
\hline Indicado pelo titular & & & 2 & 25 & 1 & 14,3 & & \\
\hline Indicado pelo prefeito & & & 3 & 37,5 & & & & \\
\hline $\begin{array}{l}\text { Convocado por ser presidente da } \\
\text { entidade }\end{array}$ & 3 & 17,6 & & & & & & \\
\hline Indicado pela instituição & 4 & 23,5 & 3 & 37,5 & 4 & 57,1 & & \\
\hline Eleito pelos pares & 9 & 52,9 & & & 2 & 28,6 & 2 & 100 \\
\hline Total & 17 & 100 & 8 & 100 & 7 & 100 & 2 & 100 \\
\hline
\end{tabular}


$\mathrm{N}$ a tabela 2, expõe-se o nível de apreensão e conhecimento dos conselheiros entrevistados sobre o conceito de C M S. As respostas foram categorizadas levandose em consideração a legislação vigente sobre o CM S. D estaca-se que $29,4 \%$ dos conselheiros responderam ser este um órgão deliberativo; 20,6\% disseram que conselho é um grupo de pessoas que discutem e buscam melhorias para saúde; e ainda 8,8\% dos conselheiros afirmaram que é um órgão de controle social.

\section{Tabela 2. N ível de apreensão e conhecimento sobre o conceito de Conselho de Saúde, Conselho Municipal de Saúde, Viçosa-M G (2006)}

\begin{tabular}{l|c|c}
\hline $\begin{array}{l}\text { Apreensão e conhecimento sobre o conceito de } \\
\text { conselho }\end{array}$ & $\mathrm{n}$ & $\%$ \\
\hline Órgão deliberativo & 10 & 29,4 \\
$\begin{array}{l}\text { Grupo de pessoas que discutem e buscam melhorias } \\
\text { para saúde }\end{array}$ & 7 & 20,6 \\
Órgão de fiscalização & 4 & 14,7 \\
Órgão para tomar decisões & 3 & 11,8 \\
Órgão de controle social & 3 & 8,8 \\
Lugar de gestão dos recursos para a saúde & 1 & 2,8 \\
Órgão de consultoria e orientação do prefeito & 1 & 2,9 \\
Instância estabelecida obrigatoriamente & 34 & 100 \\
\hline Total & & \\
\hline
\end{tabular}

Conforme está demonstrado na tabela 3, quando questionados sobre a função dosconsel heirosno CM S, a maioria dosentrevistados $(61,8 \%)$ fez referência apenas às funções diretamente ligadas ao momento das reuniões do conselho, como por exemplo: acompanhar e participar das reuniões (29,4\%); fiscalizar as ações e deliberar nas reuniões $(20,6 \%)$; deliberar nas reuniões $(8,8 \%$ ) eescutar nas reuniões (2,9\%). E ainda, 8,8\% disseram não ter função. 
Tabela 3 - Conhecimento sobre a função do conselheiro, Conselho M unicipal de Saúde, Viçosa-M G (2006)

\begin{tabular}{l|c|c}
\hline \multicolumn{1}{c|}{ Função do conselheiro } & $\mathrm{n}$ & $\%$ \\
\hline Acompanhar e participar das reuniões & 10 & $29,4 \%$ \\
Fiscalizar as ações e deliberar nas reuniões & 7 & $20,6 \%$ \\
Representar a sociedade & 7 & $20,6 \%$ \\
Deliberar nas reuniões & 3 & $8,8 \%$ \\
Não tenho função & 3 & $8,8 \%$ \\
Ter conhecimento da saúde do municipio & 2 & $5,8 \%$ \\
Implantar as decisões tomadas no CMS & 1 & $2,9 \%$ \\
Ir às reuniões para escutar & 1 & $2,9 \%$ \\
\hline Total & 34 & 100 \\
\hline
\end{tabular}

Em relação ao conhecimento dos conselheiros quanto àsfontes definanciamento do SU S no município, 58,8\% dos entrevistados disseram conhecer em partes; 29,4\% disseram conhecer para fins de avaliação; e 11,8\% não sabem informar quais as fontes de financiamento. $\mathrm{N}$ ão obstante, no que se refere ao conhecimento dos documentos relativos à prática do controlesocial no município (Regimento Interno, Plano M unicipal deSaúdee Relatório de G estão) produzidos pela SecretariaM unicipal de Saúde (SM S) e deliberados pelo C M S, 55,9\% dos entrevistados informaram ter conhecimento sobre o Regimento Interno e 44,1\% relataram não ter conhecimento deste. Q uanto ao Plano M unicipal de Saúde (PM S), 73,5\% nunca o leram; e em relação ao Relatório de G estão, 67,6\% responderam quenão sabem analisá-lo, 26,5\% disseram que sabem analisá-lo e 5,8\% que sabem analisá-lo em partes.

$\mathrm{N}$ o que concerne à capacitação e/ ou educação continuada para o exercício no CM S, observou-seque 79,4\% dos conselheiros nunca receberam nenhum tipo de capacitação e/ou educação continuada, destacando-se que 85\% relataram sentir necessidade de receber algum tipo de capacitação para atuar no CM S. Todos os conselheiros mencionaram o fato de que cursos de capacitação são fundamentais para o exercício do controle social.

\section{D iscussão}

O s resultados do estudo informam que a maioria dos consel heiros entrevistados apresentou ensino superior, o quevai ao encontro dos resultados em estudo realizado por Van Stralen et al. (2006), que constataram que cinco dosnoveconselheiros de 
nove municípios dos estados de G oiás e M ato Grosso do Sul possuíam ensino superior completo. O s mesmos autores notam haver tendência à elitização da participação nos conselhos, devido ao grau de instrução dos conselheiros ser, geralmente, mais alto do que o da média dos usuários do SU S. M ais ainda, a inserção desses conselheiros revelou-se de maneira desigual, na medida em que $37,5 \%$ dos representantes do governo municipal foram indicados pelo prefeito, ao passo que $52,9 \%$ dos representantes dos usuários foram eleitos pelos pares. As possibilidades de acesso ao Conselho pareciam variar do grupo político ao qual 0 consel heiro estava vinculado. $N$ esse sentido, pode-se supor que esse deslocamento da representatividade não é obviamente inocente (D AGN IN O , 2002).

N esta perspectiva, como assinal aTatagiba (2002), o mecanismo derepresentação no qual os representantes são indicados e escolhidos obedecendo a outros critérios que não o conhecimento, o compromisso e o poder efetivo de decisão acerca da temática em questão, limita uma articulação entre o representantee o governo que impacte positivamenteas instituições do Estado, rumo a uma maior democratização. D e forma complementar, Cohn (2003) assinala que essa elitização é expressa também pela baixa rotatividade dos conselheiros. Van Stralen et al. (2003) encontraram evidências de baixa rotatividade, visto queapenasum dos conselheiros encontrava-se no primeiro mandato. Tendo em vista que o tempo demandato são dois anos, constatou-se situação semelhante no presente estudo, sendo a maioria dos conselheiros membros do CM S há mais de um ano e que $64,7 \%$ destes já foram membros em outra gestão.

Essa baixa rotatividade dos membros do C onsel ho de Saúde pode ser explicada, provavelmente, por uma insuficiência do exercício democrático no âmbito da própria sociedade civil, permitindo que se cristalizem determinados sujeitos sociais como representantes dos distintos interesses econômicos e de demandas a partir de carências aí presentes (CO H N , 2003). 0 s consel hos devem delimitar o período de representação dos conselheiros para garantir a renovação do seu pleno elimitar a participação da mesma pessoa em várias comissões temáticas, para ampliar o número de participantes nos diferentes espaços de controle social (BRASI L, 2008).

Vale ressaltar que, segundo a Lei no 8.142/90, os C onsel hos de Saúde "atuam na formulação e proposição de estratégias e no controle da execução das políticas desaúde, inclusive em seus aspectos econômicosefinanceiros". N o mesmo sentido, a Resolução no 333/2003, na primeira diretriz, define: “O Conselho de Saúde é 
um órgão colegiado, deliberativo e permanente do Sistema Ú nico de Saúde em cada esfera do governo, que consubstancia a participação da sociedade organizada na administração da saúde, como subsistema da Seguridade Social, propiciando seu controle social" (BRASIL, 2003). No entanto, observou-se que apesar da diversidade derespostas apresentada pelos entrevistadosa respeito do papel efunção do consel ho, poucos fizeram referência ao objetivo primordial deste, apresentado pelas legislações acima citadas, ou seja, o exercício do controle social, o que pode ser observado nos depoimentos dados por al guns consel heiros:

É um órgão que determina todas as deliberações de saúde.

É onde se reúne um grupo de pessoas que falem uma linguagem só, que preocupem em resolver prioridades, um mesmo pensamento que preocupe diretamente com 0 povo sofrido.

U m lugar de reuniões que serve para fiscalizar o sistema de saúde".

Ó rgão que serve para receber reclamações e sugestões, para tomar decisões na área da saúde para população.

$\mathrm{N}$ a análise dessas respostas, chama a atenção o fato de que os conselheiros apresentam conceitos bastante divergentes em relação ao conselho, variando desde espaços deliberativos até 0 conselho como espaços de reuniões para fiscalizar 0 sistema de saúde. É possível até dizer, com base nas entrevistas, que o conceito principal de conselho - órgão de controle social - não foi o mais valorizado.

Aqui um ponto importantea destacar éque G erschman (2004), em seu estudo, também observou quepoucos entrevistadosatribuem ao consel ho o papel deexercer o controlesocial, o queé um dado preocupante, por ser este um atributo essencial deste órgão, idealizado pelo movimento da reforma sanitária e incorporado à legislação do SU S (COTTA et al., 1998). O s conselhos são locais privilegiados porque constituem canais de participação social na políticalocal, institucionalizados em 1988 e difundidos nos anos 1990. Embora haja diferenças importantes no efetivo funcionamento desse recurso de prática e fortalecimento da democracia participativa, que inspirou os constituintes, esses são, sem dúvida, canais institucionais que possi bilitam maior controle sobre as atribuições das prefeituras e ampliam a participação da sociedade (CAST RO , 2007). Inclusive, no tema "A partici pação da sociedadena efetivação do direito humano da saúde", do relatório final da 13을 Conferência N acional de Saúde realizada em 2008, fica estabelecido que para o fortalecimento do controle social, os Consel hos de Saúde devem criar 
comissões temáticas intersetoriais para aprofundar discussões sobre assuntos específicos deacordo com as necessidades locais e regionais, no sentido de garantir a qualidade da atenção aos usuários.

Q uanto ao conhecimento dos consel heiros em relação a sua função no CM S, em várias falas, a maioria dos consel hei ros limita sua função à simples participação nas reuniões; por conseguinte, consta-se a impressão de que a desinformação está mais presente do quenunca, conformeseilustra pelos depoimentos quese seguem:

Estou lá na reunião para discutir os assuntos em pauta e contribuir com aquilo que posso.

D eliberar as questões de saúde do município que estão na pauta.

Ir lá na reunião, sentar e escutar.

Este fato se torna ainda mais preocupante ao analisarmos a ampla função do consel heiro, conforme orienta o Guia do Consel heiro (BRASI L/M S, 2002, p. 31): "épapel do Conselheiro de Saúde participar na formulação das políticas de saúde, acompanhar a implantação das ações escol hidas, fiscalizar e controlar gastos, prazos, resultados parciais e a implantação definitiva dessas políticas".

0 utro ponto quemerece destaqueéo fato dequenenhum consel heiro relacionou sua função no CM S ao exercício do controle social, viabilizando a participação da sociedade junto ao governo na gestão da política de saúde. Resultado semelhantefoi obtido por Wendhausen eC aponi (2002). Isso em grande partese devea um relativo desconhecimento sobre seu papel no CM S, refletindo a ausência de capacitação para o exercício da função (BELIN I, 2005), sendo que a efetivação de suas atribuições estárelacionada com o nível deformação einformação queosconsel heiros apresentam para poder decidir e controlar as políticas públicas (CO UTIN H O , 1997).

N este sentido, Tatagiba (2002) aponta a desqualificação dos consel heiros para o exercício de suas funções como um dos principais constrangimentos à existência de uma relação mais simétrica entre Estado e sociedade. Em seu estudo, o qual consiste na análise dos conselhos gestores do Paraná, incluindo os Conselhos M unicipais de Saúde, objetivando identificar os processos decisórios no interior dosmesmos, conclui queos consel hos parecem regidos por uma lógica contraditória, marcada pela correlação entreo peso dos traços autoritários das instituições estatais brasileiras e o peso do recente adensamento da sociedade, por meio da criação de novos espaços den egociação e representação políticas. O s consel hos, nesse contexto, surgem com as ambiguidades, os desafios e as promessas de uma forma partilhada 
de construção de políticas públicas, sob a égide de uma cultura política na qual predominam referências autoritárias, direcionando-os para uma bai xa capacidade propositiva e um reduzido poder de influência sobre o processo de definição das políticas públicas. É importante enfatizar quea simples existência de um consel ho, funcionando conforme preconiza a legislação, não significa sua legitimação. Além disso, énecessário que o consel heiro conheça seu papel ea finalidade do consel ho, onde o silenciamento advindo da falta de preparo não pode ser superior à prática legal de participação e controle social (SOARES; TRIN CAUS, 2006).

Segundo Correia (2005), o tema que os conselheiros de saúde mais têm tido dificuldades em compreender é o financiamento do SU S, fato este constatado no presente estudo, onde a maioria dos consel heiros conhece apenas parcialmente as fontes de onde provêm as verbas do SUS. Esta deficiência é sempre pauta de fóruns - como plenárias, congressos e conferências - e tem sido a área em que os conselheiros mais solicitam capacitações, dada a importância de se controlar os recursos públicos, já que é a aplicação desses que desenha o rumo da política de saúde nas três esferas do governo. Por isso, cabe ao consel ho fiscalizar e controlar gastos e deliberar sobre critérios demovimentação do Fundo deSaúde. Sendo este último o meio pelo qual ocorre o repasse dos recursos federais para estados e municípios e destes para as entidades prestadoras de serviço, deveria estar sob 0 olhar atento da sociedade(TATAGIBA, 2002). Como definido na $13^{\circ}$ C onferência de Saúde (2008), os consel hos devem criar comissões permanentes de orçamento efinanças, com acesso às contas do Fundo de Saúde, para acompanhar efiscalizar a aplicabilidade dos recursos financei ros destinados às ações eaos serviços de saúde.

É válido afirmar que, na prática, os conselheiros não participam das decisões sobre alocação de recursos da saúde. Entretanto, para a concretização do controle social, torna-se indispensável a organização e o acesso às decisões, como forma de garantir a participação nas decisões do Estado, sobretudo no que tange ao financiamento da saúde. Logo, o controlesocial emergecomo efeito da participação, na medida em que esta se caracteriza pela organização e pelo acesso às decisões (GUIZARDI et al., 2004; CUNH A, et al., 2003).

Infelizmente, há ainda a ressalva, constatada em nossas análises: 41,2\% dos entrevistados não conheciam o Regimento Interno do município de Viçosa. Sabendo queesteéum dos documentos responsáveis pela estruturação dos processos de discussão e deliberação dos conselhos, tendo como objetivo disciplinar o 
funcionamento desteúltimo, o Regimento Interno deveria ser elaborado eaprovado pelo próprio plenário e conter os seguintes tópicos: natureza, finalidade e competências do conselho e sua organização quanto ao Plenário. Segundo Correia (2005), o regimento devetratar da organização administrativa e definir a forma de escolha (recomenda-se eleição entre os conselheiros), o mandato e as atribuições do presidente do consel ho e de sua coordenação.

Vale lembrar que o CM S deV içosa possui seu Regimento Interno e este dispõe sobre as atribuições e atividades do conselho (D iretrizes Básicas de Atuação, Composição, Atribuições e Funcionamento, Ó rgãos Integrantes, Plenário e M esa Diretora, C onferência M unicipal deSaúde). N o entanto, o fato demuitos conselheiros desconhecerem o R egimento Interno constitui um entrave para o funcionamento do conselho, dificultando o exercício de suas competências. Resultado semel hante foi encontrado por Presoto e Westphal (2005), que demonstraram em seu estudo que as competências estabelecidas nos regimentos não têm se efetivado na prática, porque os consel heiros não conhecem suas funções definidas pela legislação.

O utro aspecto que seguramente atua como fator dificultador do adequado exercício da função de conselheiro é o desconhecimento do Plano M unicipal de Saúde do município. Como define a Lei no 8.080/90, no Art. 36, os Planos de Saúde serão a base das atividades e programações de cada nível de direção do SU S, sendo sua elaboração obrigatória para os municípios receberem os recursos do G overno Federal. A Resolução no 333/2003, da competência dos ConselhosdeSaúde, parágrafo V eVII, delibera que os consel hos devem participar da elaboração desse plano e proceder à sua revisão periódica. Logo, é importante que essa participação ocorra em todos os momentos do planejamento, desde o diagnóstico da realidade, com o levantamento e priorização dos problemas, definição de objetivos e ações para o enfrentamento dosmesmos, atéo acompanhamento da execução do quefoi planejado e avaliação do impacto das ações implementadas (CO RREIA, 2005).

D esde essa perspectiva, o PM S deveria ser um documento de constante consulta dos conselheiros, pois através delepodeseanalisar a situação de saúde do município, avaliando o cumprimento das prioridades e ações do governo. 0 bserva-se que a elaboração do PM S se reduz ao simples cumprimento burocrático das exigências legais (Lei no 8.080/90) para municipalização, mas na prática, conformeapontam Cotta et al. (1998), o PM S não é utilizado como um instrumento de consulta para aval iação das ações e serviços de saúde pel os consel hei ros. Constata-se ainda 
que no próprio Regimento Interno do CM S de Viçosa, está explícito no Art. 7ํㅡ, parágrafo II, que uma de suas atribuições é del iberar sobre a adequação do PM S, fiscal izando, acompanhando eavaliando o cumprimento da política que orienta o plano. Isso demonstra que grande parte dos conselheiros aparenta nunca terem lido o PM S, desconhecendo também seu próprio R egimento Interno.

Em relação ao R elatório de G estão, segundo a R esolução no 333/2003, compete ao consel ho analisá-lo, discuti-lo eaprová-lo, com a prestação de contas einformações financeiras, repassadas em tempo hábil aos consel heiros, acompanhado do devido assessoramento. D e acordo com o relatório da 13ํㅡ Conferência (BRASIL, 2008) deve-se exigir dos gestores a prestação de contas e do relatório de gestão em audiências públicas, remetendo-os aos Conselhos de Saúde e divulgando-os em meio expresso e eletrônico. Por outro lado, o fato de o Relatório de G estão ser entregue aos conselheiros não efetiva o controle de custos, pois constata-se, no presente estudo, que $67,6 \%$ dos entrevistados responderam que não sabem analisálo. Portanto, a possibilidade de os conselheiros contribuírem para fiscalizar as execuçõesfinanceiras e orçamentárias do Fundo M unicipal deSaúde parece restrita. Assim sendo, a ausência de qualificação carrega para o interior desses espaços públicos uma desigualdadeadicional que podeacabar reproduzindo exatamenteo que eles têm por objetivo eliminar - 0 acesso privilegiado aos recursos do Estado que engendra a desigualdade social mais ampla (D AGN IN O , 2002).

O utra situação observada neste estudo foi que 79,4\% dos consel heiros nunca receberam nenhum tipo de capacitação. Esta falta depreparo também foi verificada no estudo de Coutinho (1997), no qual o autor relata que a falta da informação técnica por parte dos conselheiros dificulta o acompanhamento das discussões realizadas no conselho estudado. Segundo Wendhausen e Caponi (2002), os Conselhos de Saúde foram criados tendo como princípio a participação efetiva de todos os setores sociais no controle e avaliação das políticas de saúde, mas há dificuldade de queisso possa ocorrer, diante da diferença de preparo dos consel heiros.

É verdade quenão há nada que impeça a oferta de capacitações aos consel heiros visando a um entendimento maior sobre sua atuação nas políticas de saúde (BELINI, 2005). Contudo, as experiências de capacitação apresentam-se timidamente em nossa sociedade, pois a consecução desses cursos de capacitação depende, ainda, da mobilização efetiva dos diversos setores políticos e sociais da sociedade interessados na política de saúde do município. Aliás, o despreparo dos 
consel heiros para exercerem sua função pode aparecer como um interesse do poder público, conforme encontrado nos estudos de Cotta et al. (1998), Fleury et al. (1997), Fleury (2006) e Soares e Trincaus (2006).

0 problema da falta de capacitação atinge de forma diferenciada os distintos atores que participam dos conselhos, uma vez que 0 acesso às informações e 0 próprio conhecimento quanto ao funcionamento da máquina administrativa colocam os conselheiros governamentais em vantagem em relação aos representantes da sociedade civil (TATAG IBA, 2002). Ribeiro eAndrade (2003) ressaltam ainda que o caminho para o estabelecimento da participação não passa apenas pela criação de mecanismos institucionais. Para esses autores, somos levados a acreditar que, mesmo havendo uma paridade formal ejurídica na configuração dos consel hos, só se desenvolverão práticas democráticas eficazes se também a cultura política de seus conselheiros for favorável ao fortal ecimento da participação democrática. Além disso, somam-se as questões culturais, a falta de preparo técnico, a falta de conhecimento de seu papel como conselheiro e a falta de informações, motivos pelos quais muitos consel heirosficam em silêncio duranteas reuniões (COTTA et al., 1998; FLEU RY et al., 1997; FLEURY, 2006).

A desigualdade de poder e de acesso à informação entre os representantes do governo e da sociedade civil dificulta a participação mais dinâmica. Um estudo sobre a participação dos consel hei ros representantes da sociedade civil conclui que 0 silêncio desses representantes durante a maioria das reuniões é reflexo da desigualdade de poder (WEN D H AU SEN ; CAPO N I, 2002). Sabe-seque, ao lado da sociedade civil, uma série de elementos opera dificultando uma participação mais igualitária nos espaços públicos: o mais importante parece ser a exigência de qualificação - técnica e política - que essa participação coloca aos representantes da sociedade civil (D AGN IN O, 2002).

A falta de preparo dos conselheirosé um dado preocupante, e gera dificuldades para implementar as conquistas legais. D esta forma, segundo C hauí (1993), os sujeitos políticos participam da vida social em proporção ao volume equalidade das informações que possuem, em especial, a partir das suas possibilidades de acesso às fontes de informação e de condições favoráveis de aproveitamento delas, de forma a poderem intervir como produtores do saber. D e acordo com M oraes (2005), a gestão da informação, inclusive da saúde, permanece nas mãos dos que entendem, dos que sabem - enfim, dos técnicos. No campo do controle 
social, o acesso à informação é um fator essencial, uma vez que expande a capacidade de argumentação dos conselheiros nos processos decisórios e isso implica a possibilidade de os C onsel hos de Saúde deliberarem sobre a política de saúde e intervirem na realidade hoje existente. Além disso, a falta de conhecimento dos conselheiros fragiliza a comunicação entre o consel ho e os responsáveis pela execução das políticas no âmbito da administração, o que reduz a capacidade do conselho para atuar como instância geradora de maior responsabilização das agências estatais (TATAG IBA, 2002).

$D$ eve-se lembrar, ainda, que o controle social se situa como parte importante da ação política e é exercido, principalmente, por estratégias discursivas (ARAÚ J0 , 2002). Segundo Araújo (2003), a comunicação molda as atitudes e comportamentos, e se efetiva por meio de informação suficiente e adequada. A informação e conhecimento das políticas de saúde se mostram fundamentais, por instrumentalizarem os consel heiros quanto às possibilidades de suas intervenções (GU IZARD I; PIN H EIRO , 2006).

É nesse sentido que o M inistério da Saúde, as Secretarias estaduais e municipais de Saúde e os C onsel hos de Saúde, nas três esferas, devem promover e assegurar dotação orçamentária para a implantação e a implementação da Política Nacional de Educação Permanente para o Controle Social no SUS, aprovada pela R esolução CN S no 363/2006, em parceria com as instituições de ensino superior. Devem ser criados núcleos de educação permanente, para promover a inclusão social qual ificada para o controle social, formar equalificar as ações de conselheiros de saúde e todos os atores envolvidos com o SUS, contemplando temas relevantes acerca das políticas públicas de saúde e relacionadas. D esta forma, haveria maior conscientização sobre direitos e deveres, universalização das informações, autonomia para atuação no controle social, formação de representações legítimas, aumento da capacidade propositiva e de fiscalização efetiva das ações e serviços de saúde e o exercício da gestão participativa, fazendo uso de diversificados formatos, meios de comunicação, metodologias e linguagens adequadas à cultura e à realidade local, em caráter permanente (BRASIL, 2008).

D estarte, no que concerneà gestão em saúde, é preciso democratizar o processo de trabal ho na organização dos serviços, horizontalizando saberes, numa perspectiva de integralidade (PINHEIRO; LUZ, 2003). Se assim não o for, o poder 
deliberativo previsto para os conselhos gestores com frequência se transforma na prática numa função consultiva ou até mesmo apenas legitimadora das decisões tomadas nos gabinetes (D AG N IN O, 2002).

\section{Considerações finais}

0 panorama encontrado pode apontar alguns desafios deparados no Consel ho de Saúde, tais como a falta de conhecimento dos conselheiros sobre seu papel no CM S esobreo próprio papel do CM S na esfera social esanitária; o desconhecimento sobre as fontes de onde provêm as verbas quefinanciam o SU S; o desconhecimento do Regimento Interno e do Plano M unicipal de Saúde, além da dificuldade de analisar o Relatório de G estão. Tudo isso limita a eficiência da atuação dos conselheiros, levando a comportamentos de submissão e conformismo em substituição à práticas de cidadania, participação e controle social. N ota-se, com isso, que é cada vez mais necessário socializar as informações sobre os conselhos junto à sociedade, buscando reverter essa situação.

Contudo, é importante ressaltar a necessidade de ampliar o processo de empoderamento dos diferentes atores locais para fortal ecer o exercício do controle social, buscando conscientizar os Consel heiros M unicipais de Saúde sobresua função derepresentação social, eainda promover o reconhecimento do consel ho como espaço de manifestações de interesses plurais em busca do benefício de toda sociedade.

Partindo do pressuposto de que só se pode controlar aquilo que se conhece, justifica-se a necessidade contínua de cursos de capacitação e de educação continuada para os conselheiros, de modo que estes possam exercer o controle social e participar ativamente na gestão das políticas públicas de saúde.

Percebe-se que as experiências atuais de democracia participativa, como são os casos dos conselhos municipais, apontam teoricamente para um salto na instituição democrática, embora na prática ainda tenham um longo caminho a percorrer antes de aparecer como uma realidade efetiva. $N$ este sentido, a questão não é apenas criar novas modalidades de governo democrático, mas reformar a governabilidade e ampliar as bases de sustentação do jogo democrático mediante uma nova compreensão socioantropológica do mesmo, para que ele responda mais efetivamente às novas demandas de participação e aos novos desafios de gestão pública (M ARTIN S, 2008). 


\section{R eferências}

ARAÚ JO , I.S. M ercado Simbólico: interlocução, luta, poder. U m modelo de comunicação para políticas públicas. 2002. Tese(D outorado) - Escola deC omunicação, U niversidadeFederal do Rio dej aneiro, Rio de Janeiro, 2002.

. M ercado Simbólico: um modelo decomunicação para políticas públicas. Rev. Interface: comunicação, saúde, educação. v. 8, n. 4, p. 165-177, 2003.

ASSIS, M .M .A.; VILLA T.C.S. O controlesocial ea democratização da informação: um processo em construção. Revista Latino-Americana deEnfermagem, Ribeirão Preto, v. 11, n. 3, p. 376-82, 2003.

BELIN I, L.M .P. Consel ho M unicipal deSaúde de Ampére: avaliando o controle social. 2005. 52p. D issertação (M estrado em Saúde C oletiva) - U niversidade do 0 este de Santa C atarina, J oaçaba, 2005.

BRASIL. M inistério daSaúde. Lei n 8.080, de 19 deSetembro de1990. Lei O rgânica da Saúde. D ispõesobreasC ondiçõespara Promoção, Proteção eR ecuperação da Saúde, a O rganização e o Funcionamento dos ServiçosC orrespondentese dáO utras Providências. D iário 0 fidaal da República Federativa do Brasil, Brasília, D F, v. 128, n. 182, p. 18055-18059, Seção I, pt. 1, set. 1990 (a).

BRASIL. M inistério da Saúde. Lei no 8.142, de 28 de dezembro de 1990. D ispõe sobre a participação daComunidadena G estão do SistemaÚ nico deSaúde(SU S) esobreasTranferências Intergovernamentais de RecursosFinanceirosnaÁ rea da Saúde edá O utras Providências. D iário O ficial da União, Brasília, D F, v. 68, n. 249, p. 25694, Seção I, dez. 1990 (b).

BRASI L. M inistério da Saúde. R elatório Final da 13ª C onferência N acional de Saúde. Saúdee qualidade devida: políticas de estado e desenvolvimento. Brasília: M inistério da Saúde, 2008.

BRASIL. M inistério daSaúde. Resolução no 333, de 4 denovembro de2003. Aprova as diretrizes para criação, reformulação, estruturação efuncionamento dos conselhos de saúde. D iário 0 ficial da U nião, 2003, Braślia, D F, n. 236, p. 57, nov. 2003. Seção 1.

BRASIL. M inistério da Saúde. Secretaria deG estão del nvestimentosem Saúde. D epartamento de Gerenciamento del nvestimentos. G uia do conselherro: curso de capacitação deconselheirosestaduais emunicipais desaúde. Braślia: M inistério da Saúde, 2002.

CASTRO , I.E. D o espaço político ao capital social. 0 problema da sobre-representação dos municípios pequenos. Redes, v. 12, n. 2, p. 56-72, 2007.

CH AU Í, M arilena deSouza. Cultura edemocracia: o discurso competenteeoutrasfalas. São Paulo: Cortez, 1993. 367p.

$\mathrm{COH} \mathrm{N}, \mathrm{A}$. Estado esociedadee as reconfigurações do direito à saúde. Ciência eSaúdeC oletiva. São Paulo, v. 8, n. 1, p. 8-12, 2003.

CORREIA, M aria Valéria C. D esafi ospara o controlesocial. Rio de Janeiro: Fiocruz, 2005. 278p. 
COTTA, R.M . M .; M EN D ES, F.F.; M U N IZ, J.N . D escentralização daspolíticaspúblicasdesaúde: do imaginário ao real. Viçosa: UFV/CEBES, 1998. 148p.

COTTA, R.M .M . et al. Sobreo conhecimento ea consciência sanitária brasileira: o papel estratégico dosprofissionais eusuáriosno sistema sanitário. Revista Ciência eSaúde Coletiva, PaulaC ândido, v. 16, n. 16, p. 1-8, 2006.

CO U TIN H O , J.A. A participação popular na gestão da saúdeem São Paulo. LutasSociais, v.2, p. 125-140, 1997.

CUNHA, Sheila Santos. 0 controle social e seus instrumentos. Disponível em: বhttp:// www. ad m.ufba.br/capital social / D ocumen tos\% 20 para\% 20 download/ Controle\%20Social\%20e\%20Seus\%20Instrumentos.pdf>. Acesso em: 27 mai. 2008.

D AG N IN O , Evelina. Sociedade civil, espaços públicos ea construção democrática no Brasil: limitese possibilidades. In: . Soci edadecivil eespaçospúblicosno Brasil. São Paulo: Paze Terra, 2002, p. 279-301.

FLEU RY, S. et al. M unicipalização da Saúdeeo Poder Local no Brasil. Revista deAdministração Pública, Rio deJaneiro, v. 21, n. 3, p. 196-206, 1997.

FLEU RY, Sônia. D emocracia, descentralização edesenvolvi mento: Brasil eEspanha. Rio dej aneiro: FGV, 2006. 508p.

GERSCH M AN , S. Conselhos M unicipais deSaúde: atuação erepresentação das comunidades populares. CadernosdeSaúdePública, Rio dejaneiro, v. 20, n. 6, p. 1670-1681, 2004.

GUIZARDI, F.L. et al. Participação da comunidadeem espaços públicosdesaúde: umaanálisedas Conferências N acionais deSaúde. Physis, Rio de Janeiro, v. 14, n. 1, p. 15- 39, 2004.

GUIZARD I, F.L.; PIN H EIRO, R. Dilemas culturais, sociais e políticos da participação dos movimentos sociaisnos Conselhos de Saúde. Ciência eSaúdeC oletiva, Rio deJaneiro, v. 11, n. 3, p. 797-805, 2006.

IN ST ITUTO BRASI LEIRO DE GEO GRAFIA E ESTAT ÍSTICA. Censo D emográfico 2000. (CD-RO M ). Rio de Janeiro, 2000.

M ART IN S, Paulo H enrique 0 embaraço democrático eos desafios da participação. In: M ART IN S, P.H .; M ATT OS, A.; FO N TES, B. (org.). Limitesda democracia. v. 1. Recife: Editora daU FPE, 2008. p. 3-250.

M O RAES, I.H .S. Política N acional deI nformação, InformáticaeC omunicação em Saúde: um pacto a ser construído. Saúdeem D ebate, Rio deJaneiro, v. 29, n. 69, p. 86-98, 2005.

PIN H EIRO , R.; LUZ, M . T. Práticas eficazes x modelosideais: ação e pensamento na construção da integralidade. In. PIN H EIRO , R.; M ATTO S, R.JR ...(org.). Consrução da integralidade cotidiano, saberesepráticas em saúde. Rio deJ aneiro: C epesc, 2003. 
PRESOTO , L.H .; WEST PH AL, M .F. A participação social na atuação dos conselhosmunicipais deBertioga- SP. SaúdeeSociedade, São Paulo, v. 14, n. 1, p. 68-77, 2005.

PRO GRAM A DASN AÇÕ ESUN ID AS PARA O DESEN V O LVIM EN TO . Instituto dePesquisa Econômica Aplicada(IPEA) eFundação J oão Pinheiro (FJP). Atlas do D esenvolvimento H umano no Brasil/Índice deD esenvolvimento H umano M unicipal. D isponível em: http://www.ipea.gov.br/ . Acesso em: 15 abr. 2008.

RIBEIRO , E.A.; AN D RADE, C.M . Culturapolíticaeparticipação diferenciada: o caso do C onselho M unicipal deSaúdedo município deD oisVizinhos, Estado do Paraná. Acta Scientiarum. H uman and Social Sciences, M aringá, v. 25, n. 2, p. 349-358, 2003.

SILVA, A.X.; CRUZ, E.A.; M ELO , V. A importância estratégica da informação em saúde parao exercício do controlesocial. Revista Ciência eSaúdeC oletiva, Rio deJaneiro, v. 12, n. 3, p. 683688, 2007.

SO ARES, L.G.;TRIN CAUS, M .R. Participação e controle social: uma revisão bibliográfica dos avançose desafios vivenciadospelos conselhos de saúde. Revisła Eletrônica Lato Sensu, n. 1, p. 245 264, 2006.

TATAG IBA, Luciana. O sconselhosgestoresea democratização das políticas públicasno Brasil. In: D AG N IN O , E. (org.). Sociedadeci vil eespaçospúblicosno Brasil. São Paulo: Paz eTerra, 2002. p. 47-103.

VAN ST RALEN , C.J. et al. Conselhos de saúde: efetividade do controle em municípios de G oiás e M ato Grosso do Sul. Revista Ciência eSaúdeC oletiva, Rio deJaneiro, v. 11, n. 3, p. 621632, 2006.

W EN D H AU SEN , A.; CAPO N I, S. 0 diálogo ea participação em um consel ho de saúdeem Santa C atarina, Brasil. CadernosdeSaúdePública, Rio deJaneiro, v. 18, n. 6, p. 1621-1628, 2002.

\section{N otas}

* Este estudo faz parte do projeto de pesquisa intitulado "Consolidação do Sistema Ú nico de Saúde: a estratégia de Saúde da Família enquanto instrumento de reorganização do sistema de saúde local e estímulo a participação social", foi financiado pela FAPEM IG EDT - Processo nº. 075/05- 2005.

${ }^{1}$ Salário mínimo de referência $=\mathrm{R} \$ 380,00$ 
Abstract

Participation, social control and exercise of citizenship: (dis)information asan obstacle to health counselors

To strengthen the exercise of social control in health politics, it is really necessary to know the $U$ nified $H$ ealth System; the legislation; the epidemiological reality, assistance, financial, political, and so on. In this sense, this paper aims to analyze the level of information and knowledge of the $M$ unicipal $\mathrm{H}$ ealth C ounselors in the city of Viçosa, M inas G erais State, concerning their attributions and functions. The elements of analysis of the study were semi-structured interviews conducted from April to July 2006, and the direct observation of meetings. From 44 counselors, 34 (77.3\%) were interviewed, 17 (50\%) are users' representatives; eight (23.5\%) are representatives of the municipal government; seven $(20.6 \%)$ are representatives of the service; and two (5.9\%) are representatives of health professionals. It can be noticed that $41.2 \%$ of counselors ignore the Internal Regiment, what could hinder the fulfillment of their competences. The health plan is not used for evaluation of health actions and services for the counselors, because most of them (73.5\%) declared not having read it. The possibility of counselors helping supervise the financial and budgetary executions of the M unicipal $\mathrm{H}$ ealth Fund restrains it, since $67.6 \%$ of the interviewees cannot analyze the administration report; $79.4 \%$ of the counselors never received training and $85 \%$ told need being qualified to act in the council. Participation and social control provide transparence to the public good and, based on the premise that one can only control what one knows, the need of continuing training courses for counselors is confirmed.

> Key words: Municipal Council of Health, Counselors of Health, Training, Social Participation, Social Control. 